Supplement of Hydrol. Earth Syst. Sci., 20, 991-1030, 2016

http://www.hydrol-earth-syst-sci.net/20/991/2016/

doi:10.5194/hess-20-991-2016-supplement

(C) Author(s) 2016. CC Attribution 3.0 License.

(c) (i)

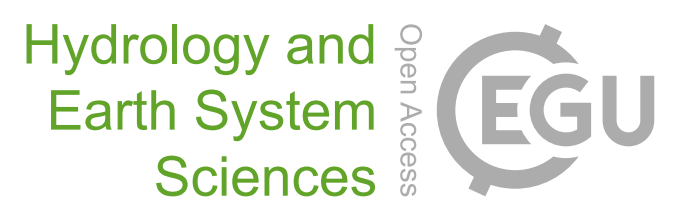

Supplement of

\title{
Linking biogeochemistry to hydro-geometrical variability in tidal estuaries: a generic modeling approach
}

Chiara Volta et al.

Correspondence to: Chiara Volta (cvolta@ulb.ac.be)

The copyright of individual parts of the supplement might differ from the CC-BY 3.0 licence. 


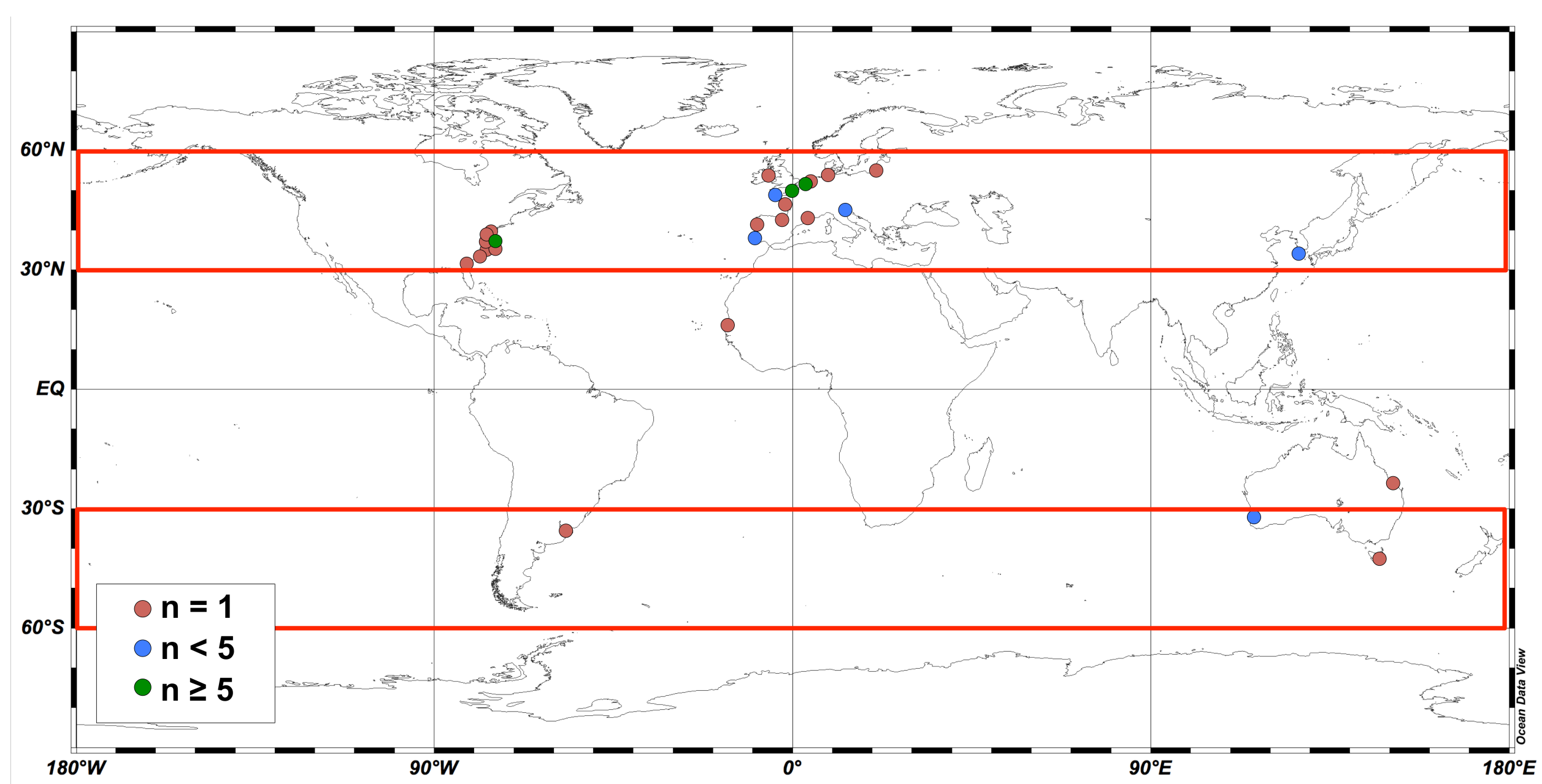

Location of published estuarine biogeochemical model applications $(\mathrm{n}=51)$ and their distribution amongst different climatic zones. Red, blue and green dots correspond to locations in which 1, and less than 5 or more than 5 model applications have been published, respectively. The limits of the temperate zones $\left(30^{\circ}<1 \mathrm{at}<60^{\circ}\right)$ in either hemisphere are highlighted in red. 